\title{
QuickVue Influenza $A+B$ rapid test for influenza surveillance in community
}

\author{
Calvin KY Cheng ${ }^{1 *}$, Dennis KM Yip ${ }^{1}$, Kwok Hung Chan², JS Malik Peiris ${ }^{3}$, Benjamin J Cowling \\ From Institut Pasteur International Network Annual Scientific Meeting \\ Hong Kong. 22-23 November 2010
}

\section{Background}

Rapid diagnosis of influenza not only facilitates timely clinical management, time series test results can also serve for disease surveillance purpose. We evaluated the performance of a community based system using QuickVue Influenza A+B test (Quidel Corp., San Diego, California) for influenza surveillance in Hong Kong.

\section{Methods}

As part of a large community study, subjects older than 2 years reporting at least two symptoms of influenzalike-illness were recruited from 30 outpatient clinics in Hong Kong prospectively from February 2007 to July 2010 around the influenza seasons [1,2]. Each subject provided a pooled pair of nose and throat swabs to be tested by the QuickVue rapid test on site. Overall test positive rate were weekly aggregated and compared with a hospital laboratory surveillance system (Weekly influenza virus isolation rate from the Queen Mary Hospital, Hong Kong) and a pre-existing community influenza sentinel surveillance system (Weekly consultation rate of influenza-like illness reported by general practitioners in private practice from the Centre of Health Protection, Department of Health, HKSAR).

\section{Results}

A total of 5,824 subjects were recruited throughout the study. We define each study week as either high influenza activity or low influenza activity using fixed thresholds after removing extreme values two standard deviations above the mean. The sensitivity of QuickVue data for picking up high influenza activity was $78 \%$ when compare with the laboratory data and was 100\% when comparing with the community data.

\section{Conclusion}

Although the sensitivity of QuickVue Influenza A+B test decreases with specimen viral load, in which may miss out mild influenza infection cases [3], its excellent specificity allows more accurate influenza surveillance when compare with other syndromic based systems. Its pointof-care usage and easy-to-use nature also increase the flexibility and popularity for disease surveillance, especially in resource limited setttings where laboratory facilities and expertise are not available.

\section{Author details}

'Department of Community Medicine and School of Public Health, The University of Hong Kong, Hong Kong SAR. ${ }^{2}$ Department of Microbiology, Queen Mary Hospital, Hospital Authority, Hong Kong, Hong Kong SAR. ${ }^{3}$ HKU Pasteur Research Centre, Hong Kong, Hong Kong SAR.

Published: 10 January 2011

\section{References}

1. Cowling BJ, Fung ROP, Cheng CKY, et al: Non-pharmaceutical interventions for influenza prevention in households - pilot findings of a large cluster randomized controlled trial in Hong Kong. PLOS ONE 2008, 3:e2101.

2. Cowling BJ, Chan KH, Fang VJ, et al: Face Masks and Hand Hygiene to Prevent Influenza Transmission in Households: A Cluster Randomized, Controlled Trial. Ann Intern Med 2009, 151:437-446.

3. Cheng CKY, Cowling BJ, Chan KH, et al: Factors affecting QuickVue Influenza $\mathrm{A}+\mathrm{B}$ rapid test performance in the community setting. Diagn Microbiol Infect Dis 2009, 65:35-41.

doi:10.1371/journal.pone.0002101

Cite this article as: Cheng et al:: QuickVue Influenza A+B rapid test for influenza surveillance in community. BMC Proceedings 2011 5(Suppl 1): P60.

\footnotetext{
* Correspondence: chengkyc@hku.hk

'Department of Community Medicine and School of Public Health, The University of Hong Kong, Hong Kong SAR

Full list of author information is available at the end of the article
}

(c) 2011 Cheng et al; licensee BioMed Central Ltd. This is an open access article distributed under the terms of the Creative Commons 